\title{
Sen's Multi Objective Optimization (M00) Technique-An Extension
}

\author{
Chandra Sen
}

Professor (Retired), Department of Agricultural Economics, Institute of Agricultural Sciences, Banaras Hindu University, Varanasi-221005, India.

\section{To Cite this Article}

Chandra Sen, "Sen's Multi Objective Optimization (MO0) Technique-An Extension”, International Journal for Modern Trends in Science and Technology, 6(9): 73-76, 2020.

\section{Article Info}

Received on 12-August-2020, Revised on 20-August-2020, Accepted on 27-August-2020, Published on 07-September-2020.

\section{ABSTRACT}

Linear programming has been very popular for achieving (maximizing or minimizing) a single objective with certain constraints. However, when objectives are more than one, linear programming becomes inefficient. Sen's multi-objective optimization (MOO) technique [1] is efficient in achieving multiple objectives simultaneously. Few modifications in Sen's MOO technique are proposed for improving its applicability for solving multi-objective optimization problems.

KEYWORDS: Multi-Objective Optimization; Linear programming; Weighted sum technique; Averaging techniques.

\section{INTRODUCTION}

Multi-objective optimization is a process of achieving a set of conflicting objective functions for generating an acceptable compromise solution. Goal programming, weighted sum technique, Lexicographic technique have been in use to solve the multi-objective optimization problems. Subjectivity in fixing the goals, weights or priority in achieving the objectives are the limitations of the methods. Sen's MOO technique is more efficient than other techniques of optimizing the multiple conflicting objectives [12]. Sen's MOO technique has been used successfully in agriculture for optimizing the resources use for increasing the income and employment with minimum use of fertilizer, irrigation, plant protection chemicals etc. [2][3][4][5][6][7][8][9][11][13]. Few modifications are proposed in Sen's MOO technique for making it more comprehensive and useful.

\section{Sen's Multi-ObJective Optimization TEChNIQUE}

The mathematical form of MOO technique is as follows:

Optimize $\mathbf{Z}=\left[\operatorname{Max} . Z_{1}\right.$, Max. $Z_{2} \ldots \ldots$ Max. $Z_{\mathrm{r}}$ Min. $Z$ r+1......Min. $\left.Z_{\mathrm{s}}\right]$

\section{Subject to:}

$$
\mathrm{AX}=\mathrm{b} \text { and } \mathrm{X} \geq 0
$$

The individual optima are obtained by optimizing each objective separately as:

$Z_{\text {optima }}=\left[\Theta_{1}, \Theta_{2} \ldots \ldots \ldots \Theta_{\mathrm{s}}\right]$

The multi-objective function is formulated as:

Maximize, $Z=\frac{\sum_{j=1}^{r} Z j}{\left|\Theta_{j}\right|}-\frac{\sum_{j=r+1}^{s} Z j}{\left|\Theta_{r+1}\right|}$

\section{Subject to:}

$$
\begin{aligned}
& A X=b \quad \text { and } X \geq 0 \\
& \Theta_{j} \neq 0 \quad \text { for } J=1,2 \ldots \ldots \ldots . . .
\end{aligned}
$$

Where $\left|\Theta_{j}\right|$ is maxima of $j^{\text {th }}$ Objective function $\left|\Theta_{r+1}\right|$ is minima of $(r+1)^{\text {th }}$ Objective function 
The objective functions may be of different dimensions. The multi-objective function is formulated by weighting each objective function with the inverse of the individual optima. This makes the each objective function dimensionless. The sum of the deviations of weighted objective functions of maximization and minimization is maximized to obtain the compromise solution.

\section{Modifications in Sen's MOO Technique}

The combined objective function can be formulated by weighting the individual objective functions with the inverse of arithmetic average, geometric average and harmonic average of the optimal and sub-optimal values of the respective objective functions as explained below:

$$
\begin{aligned}
& \text { Maximize, } \mathrm{Z}=\frac{\sum_{j=1}^{r} Z \mathrm{j}}{\mathrm{AA} \Theta_{j}, G M \Theta_{j}, H M \Theta_{j}}- \\
& \frac{\sum_{j=r+1}^{s} Z \mathrm{j}}{\mathrm{AA} \Theta_{r+1}, \mathrm{GM} \Theta_{r+1}, \mathrm{HA}_{r+1}} \\
& \text { Subject to: } \\
& \mathrm{AX}=\mathrm{b} \quad \text { and } \mathrm{X} \geq 0
\end{aligned}
$$

Where, AA, GM and HM are arithmetic, geometric and harmonic means of the optimal and sub optimal values of each objective function. The following example has been solved using the modified techniques.

\section{Example:}

Max. $Z_{1}=6 \mathrm{X}_{1}+9 \mathrm{X}_{2}+12 \mathrm{X}_{3}+5 \mathrm{X}_{4}+10 \mathrm{X}_{5}$

Max. $Z_{2}=27 X_{1}+8 X_{2}+10 X_{3}+3 X_{4}+X_{5}$

Min. $Z_{3}=21 X_{1}+3 X_{2}+4 X_{3}+8 X_{4}+5 X_{5}$

Min. $Z_{4}=12 X_{1}+1.5 X_{2}+12 X_{3}+X_{4}+3 X_{5}$

\section{Subject to:}

$$
\begin{aligned}
3 \mathrm{X}_{1}+\mathrm{X}_{2}+2 \mathrm{X}_{3}+\mathrm{X}_{4}+\mathrm{X}_{5} & =8 \\
\mathrm{X}_{2} & \geq 0.3 \\
\mathrm{X}_{4} & \geq 1.1 \\
\mathrm{X}_{5} & \geq 0.6
\end{aligned}
$$

\section{Solution}

The example was solved using linear programming for achieving all the objectives individually. It is clear from the following table that the solutions of all the four objectives are different. The process of individual optimization has optimized the particular objective function only and ignored the remaining objective functions. The maximization of first objective function $Z_{1}$ has achieved the highest value 74.2. Similarly, the

\begin{tabular}{|c|c|c|c|c|c|c|c|c|}
\hline \multirow{2}{*}{ Item } & \multicolumn{4}{|c|}{ Individual Optimization } & \multirow{2}{*}{$\begin{array}{l}\text { Sen's } \\
\text { MOO }\end{array}$} & \multicolumn{3}{|c|}{ Sen's modified MOO } \\
\hline & Max.ZZ & ${\operatorname{Max} . Z_{2}}_{2}$ & Min.Z $Z_{3}$ & $\operatorname{Min} . Z_{4}$ & & $\mathbf{A A}$ & GM & HM \\
\hline $\mathbf{X}_{\mathbf{i}}$ & $\begin{array}{c}0,0.3 \\
0\end{array}$ & $\begin{array}{c}2,0.3 \\
0\end{array}$ & $\begin{array}{c}0,0.3 \\
3\end{array}$ & $\begin{array}{c}0,0.3 \\
0\end{array}$ & $\begin{array}{c}0,6.3,0 \\
1.1,0.6\end{array}$ & $\begin{array}{c}0,6.3,0 \\
1.1,0.6\end{array}$ & $\begin{array}{c}0,6.3 \\
0\end{array}$ & $\begin{array}{c}0,6.3 \\
0\end{array}$ \\
\hline & $1.1,6.6$ & $1.1,0.6$ & $1.1,0.6$ & $7.1,0.6$ & & & $1.1,0.6$ & $1.1,0.6$ \\
\hline $\mathrm{Z}_{1}$ & 74.2 & 26.2 & 50.2 & 44.2 & 8.2 & 68.2 & 68.2 & 68.2 \\
\hline $\mathbf{Z}_{2}$ & 12.3 & 60.3 & 36.3 & 24.3 & 54.3 & 54.3 & 54.3 & 54.3 \\
\hline $\mathbf{Z}_{3}$ & 42.7 & 54.7 & 24.7 & 60.7 & 30.7 & 30.7 & 30.7 & 30.7 \\
\hline $\mathbf{Z}_{4}$ & 21.35 & 27.35 & 39.35 & 9.35 & 12.35 & 12.35 & 12.35 & 12.35 \\
\hline
\end{tabular}
individual optimal values for objective functions 2 , 3 and 4 are $60.3,24.7$ and 9.35 respectively. There is conflict amongst all the four objectives. These objectives have been optimized using Sen's MOO technique and its modifications using arithmetic average, geometric average and harmonic average. The results are presented in the following table.

Table: Solution of individual and multi-objective optimizations.

All the four results of multi-objective optimizations are unique. The Sen's modified MOO techniques are equally efficient in generating the compromising solutions for conflicting multi-objective optimization problems. The values of all the objective functions are not equal to their respective individual optima, but closer to them. The value of first objective is 68.2 which is lesser than its individual optimum 74.2 but higher that its achievements in the remaining objectives. The analysis reveals that Sen's MOO technique and its modified techniques have been found efficient in optimizing multiple conflicting objectives simultaneously.

\section{v. Conclusion}

Sen's MOO technique is simple and efficient to solve multi-objective optimization problems. Few modifications are proposed to make the technique more useful. The arithmetic mean, geometric mean and harmonic mean techniques for solving multi-objective optimization problems are formulated and tested with a suitable example. 
The solution reveals that Sen's MOO technique and the arithmetic mean, geometric mean and harmonic mean techniques are equally efficient.

\section{REFERENCES}

[1] Sen, Chandra, 1983. A new approach for multi-objective rural development planning, The Indian Economic Journal, Vol.30, (4), 91-96.

[2] Dubey, P.P. (1990) An Integrated Rural Development Plan for Jaunpur District of Eastern Uttar Pradesh (A Muli-objective Programming Approach). Ph.D. thesis. Department of Agricultural Economics, Institute of Agricultural Sciences, Banaras Hindu University, Varanasi.

[3] Gangwar, L. S.,1994. Technological Advancements and its Implications on Sustainable Agriculture- A Case Study of Nainital Tarai of Uttar Pradesh. Ph.D. thesis, Department of Agricultural Economics, Institute of Agricultural Sciences, Banaras Hindu University, Varanasi, India.

[4] Sen, Chandra and P.P. Dubey, 1994. Resource use planning in Agriculture with single and Multi-objective programming approaches (A comparative study). Journal of Scientific Research, 44, 75-81.

[5] Singh, V. K., 2002. Agricultural Development and Environmental Pollution- A Case Study of District Varanasi. Ph.D. thesis, Department of Agricultural Economics, Institute of Agricultural Sciences, Banaras Hindu University, Varanasi, India.

[6] Sinha, H. K., 2002. Effect of Air Pollution on Peri-Urban Agriculture in Varanasi. Ph.D. thesis, Department of Agricultural Economics, Institute of Agricultural Sciences, Banaras Hindu University, Varanasi, India.

[7] Singh, P. K., 2005. Multilevel multi-objective planning for Agriculture for district Mau, U.P. Ph.D. thesis. Dept. of Agricultural Economics, Institute of Agricultural Sciences, Banaras Hindu University, Varanasi, India.

[8] Kumar, H., 2012. Economic Analysis of Fresh Water Aquaculture in Maharajganj district of Eastern Uttar Pradesh. Ph.D. thesis, Department of Agricultural Economics, Institute of Agricultural Sciences, Banaras Hindu University, Varanasi, India.

[9] Gautam, K., 2013. Natural and Human Resource Use Planning for Vindhyan Region of Eastern Uttar Pradesh . Ph.D. thesis, Department of Agricultural Economics, Institute of Agricultural Sciences, Banaras Hindu University, Varanasi, India.

[10] Kumari, M., Singh, O.P. and Meena, D.C., 2017. Optimizing cropping pattern in Eastern Uttar Pradesh using Sen's Multi Objective Programming Approach, Agricultural Economics Research Review, Vol.30(2),285-291.

[11] Mukesh Kumar Maurya, 2018. Livelihood Security of Farmers in Eastern Uttar Pradesh-An Economic Analysis. Ph.D. thesis. Department of Agricultural Economics, Institute of Agricultural Sciences, Banaras Hindu University, Varanasi.

[12] Chandra Sen ,2018. Sen's Multi-Objective Programming Method and its Comparison with Other Techniques. American Journal of Operational Research, Vol. 8 (1): 10-13.

[13] Offar Gwandi (2019) Farmers' Livelihood Strategies by Optimizing Resource use in Farming Area of Varanasi, Uttar Pradesh, India, Ph.D. thesis. Department of Agricultural Economics, Institute of Agricultural Sciences, Banaras Hindu University, Varanasi. 